\section{Cerebral air embolism during endoscopic retrograde cholangiopancreatography: treatment with therapeutic hypothermia}
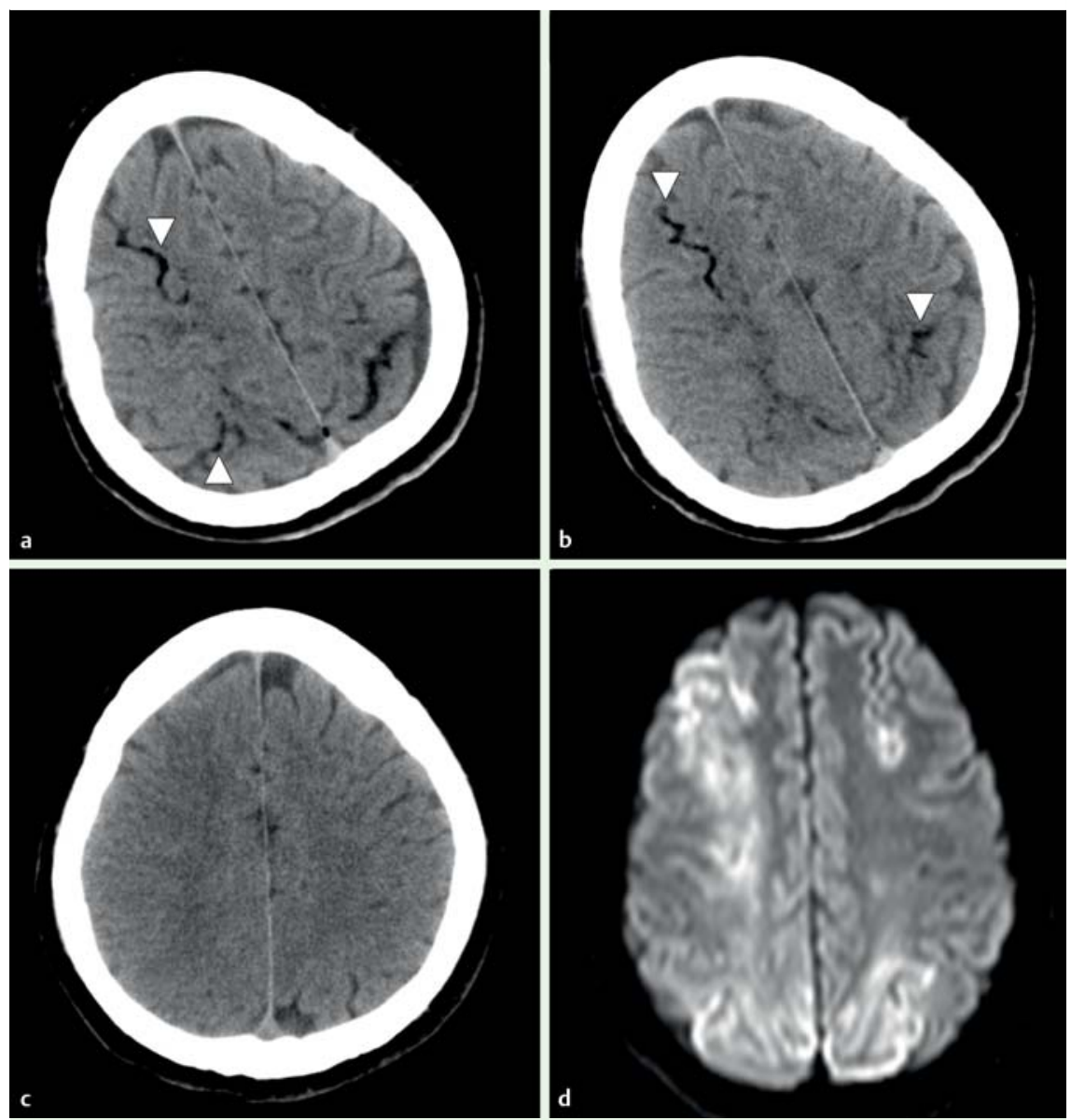

Fig. 1 Cerebral air embolism images in a patient who underwent endoscopic retrograde cholangiopancreatography. a, b Computed tomography (CT) of the brain 1 hour after symptom onset revealed multiple cerebral air emboli (arrowheads). c 24 hours later, CT brain showed complete resolution of the air bubbles and sulci effacement. $\mathbf{d}$ Diffusion weighted magnetic resonance imaging of the brain confirmed areas of acute ischemia involving middle and posterior cerebral arteries bilaterally.

Cerebral air embolism (CAE) during endoscopic retrograde cholangiopancreatography (ERCP) is an uncommon complication, but of the nine previously reported cases, seven had fatal outcomes and one was left with severe hemiparesis [1 - 3].

A 36-year-old man who was admitted with gallstone pancreatitis underwent two unsuccessful ERCPs and a successful percutaneous transhepatic cholangiogram. At subsequent ERCP for stent removal 5 days later, he suddenly became unresponsive with left conjugate eye deviation. Computed tomography (CT) of the brain confirmed CAE ( Fig.1a,b, arrowheads), which had completely resolved on imaging
24 hours later ( Fig. 1 c). Due to a lack of facilities, hyperbaric oxygen (HBO) therapy was not administered and he underwent therapeutic hypothermia for 24 hours. Subsequent examination revealed quadraparesis, which was worse on the left side. CT chest and transthoracic echocardiography were normal. Magnetic resonance imaging of the brain confirmed bilateral ischemic infarctions ( $\bullet$ Fig. 1 d). However, he made a progressive recovery, and was discharged with a mild left hemiparesis on Day 36.

Mechanical irritation or damage to the bile ducts by the endoscope, stent or high pressure air insufflated during ERCP are proposed mechanisms of communication between the biliary system and the circulation $[2,4]$. Air can reach the arterial circulation via retrograde flow or shunt through the venous system or large volumes $(>30 \mathrm{~mL})$ can directly transverse the pulmonary vasculature [5].

Risk factors include previous interventions or inflammation to the biliary tree, trauma to the liver, sphincterotomy, metal stent placement, hepatic tumors, and high pressure air insufflation. Using $\mathrm{CO}_{2}$ for insufflation can reduce the risk of air emboli, postprocedural pain, and flatus [6].

If embolism is suspected, immediate high flow oxygen and volume expansion should be initiated and the patient placed in the Trendelenburg position. Based on previous case series, early treatment with HBO has been recommended to improve outcomes [7].

HBO was unavailable for the current case and our patient underwent therapeutic hypothermia, which has been shown to improve outcomes in patients after global ischemia following cardiac arrest $[8,9]$. The first case of its use in a patient with CAE has been reported with good outcomes [10].

Focal neurological deficits during ERCP should alert physicians to the possibility of CAE. HBO remains the recommended treatment. Therapeutic hypothermia may have improved the prognosis for our patient, but further studies are needed.

Endoscopy_UCTN_Code_CPL_1AM_2AZ

Competing interests: None

\section{Dilan Athauda ${ }^{1}$, Garryck S. Tan ${ }^{2}$,} Eduardo De Pablo-Fernandez ${ }^{1}$

1 Neurology Department, Darent Valley Hospital, Dartford, United Kingdom 2 Neuroradiology Department, Darent Valley Hospital, Dartford, United Kingdom

\section{References}

1 Angelini G, Benedetti G, Chilovi F et al. Major early complications from diagnostic and therapeutic ERCP: a prospective multicenter study. Gastrointest Endosc 1998; 48: 1 - 10

2 Nern C, Bellut D, Husain N et al. A fatal cerebral venous air embolism during endoscopic retrograde cholangiopancreatography case report and review of the literature. Clin Neuroradiol 2012; 22: 371-374

3 Vachalová I, Ernst S, Vynogradova I et al. Cerebral air embolism via port catheter and endoscopic retrograde cholangio-pancreatography. Springerplus 2013; 2: 477 
4 Rabe C, Balta Z, Wüllner U et al. Biliary metal stents and air embolism: a note of caution. Endoscopy 2006; 38: 648-650

5 Rangappa P, Uhde B, Byard RW et al. Fatal cerebral arterial gas embolism after endoscopic retrograde cholangiopancreatography. Indian J Crit Care Med 2009; 13: 108-112

6 Donepudi S, Chavalitdhamrong D, Pu L et al. Air embolism complicating gastrointestinal endoscopy: a systematic review. World J Gastrointest Endosc 2013; 5: 359-365

7 Van Hulst RA, Drenthen J, Haitsma J. Effects of hyperbaric treatment in cerebral air embolism on intracranial pressure, brain oxygenation, and brain glucose metabolism in the pig. Crit Care Med 2005; 33: 841 - 846
8 Wu TC, Grotta JC. Hypothermia for acute ischaemic stroke. Lancet Neurology 2012; 12: $275-284$

9 Moore EM, Nichol AD, Bernard SB et al. Therapeutic hypothermia: benefits, mechanisms and potential clinical applications in neurological, cardiac and kidney injury. Injury 2011; 42: $843-854$

10 Inoue S, Takizawa H, Yamamoto Y et al. Therapeutic hypothermia for severe cerebral air embolism complicating pleural lavage for empyema. Interact Cardiovasc Thorac Surg 2013; 17: 199-201
Bibliography

Dol http://dx.doi.org/ 10.1055/s-0034-1364956 Endoscopy 2014; 46: E151-E152 (c) Georg Thieme Verlag KG Stuttgart · New York ISSN 0013-726X

\section{Corresponding author} Dilan Athauda, MBBS

Neurology Department Darent Valley Hospital

Dartford

United Kingdom

Fax: +44-20-32991463

dilanathauda@doctors.org.uk 